\title{
Diagnosis of microcytic hypochromic anemia with red blood cell survival via carbon monoxide breath-red blood cell survival
}

\author{
Luqian $\mathrm{LI}^{1}$, Huimin $\mathrm{DENG}^{2}$, Wen $\mathrm{MA}^{2}$, Yiwen $\mathrm{ZHOU}^{2 *}$
}

\begin{abstract}
Measuring red blood cell survival (RBCS) by a carbon monoxide breath test can help diagnose and analyze disease type and progression of anemia. In this study, we reported the application of RBCS in the differential diagnosis of thalassemia and iron deficiency anemia (IDA). A total of 233 patients were selected in this study, including 48 IDA, 60 thalassemia, and 125 healthy individual controls. The endogenous alveolar $\mathrm{CO}$ of each subject was measured by RBCS-01 red blood cell lifespanmeter to obtain the RBCS values. The mean RBCS for mild $\beta$-thalassemia, severe $\beta$-thalassemia, $\alpha$-thalassemia, IDA and the control were $67.5 \pm 22.0,31.3 \pm 13.9,69.3 \pm 27.7,78.2 \pm 28.2$ and $114.3 \pm 33.8$ days, respectively $(\mathrm{P}<0.05)$. RBCS values for thalassemia and IDA patients showed obvious shorter lifespan compared to healthy controls. The cutoff points for thalassemia, IDA and control were $<72.5$ and $<83.5$, respectively. RBCS showed a strong positive correlation to red blood cells (RBC) and hemoglobin (HGB) in thalassemia patients. In IDA patients, RBCS demonstrated a moderate positive correlation with HGB, mean corpuscular volume $(\mathrm{MCV})$, mean corpuscular hemoglobin $(\mathrm{MCH})$, mean corpuscular hemoglobin concentration $(\mathrm{MCHC})$, and red cell distribution width (RDW). There were significant differences between RBCS in different types of thalassemia. RBCS by endogenous alveolar $\mathrm{CO}$ testing is a rapid and reliable method for the differential diagnosis of thalassemia and IDA.
\end{abstract}

Keywords: red blood cell survival; differential diagnosis; thalassemia; iron deficiency anemia; endogenous alveolar CO.

Practical Application: RBCS provides an excellent diagnostic accuracy through CO breath test. Combined with other red blood cell indices, the use of RBCS contributes to the clinical differential diagnosis of thalassemia and IDA, distinguishing between severe $b$-thalassemia and mild b-thalassemia or \pm -thalassemia. The determination of erythrocyte lifespan will contribute to a comprehensive analysis of the etiology of anemia and serve as guide for customized treatment options.

\section{Introduction}

Haemolysis occurs in many haematologic, non-haematologic diseases and transfusion of stored blood. $\alpha$ and $\beta$ thalassemia are characterized by small cell, hypochromic anemia and are often misdiagnosed as iron deficiency anaemia (IDA). The potential mechanisms associated with transfusion-related toxicity remain controversial, and the relative contribution of intra- vs extra-vascular haemolysis is still under discussion (Rapido, 2017). When there is microcytic anemia but iron therapy is not improved or anemia, especially in high-risk groups, the characteristics of thalassemia should be considered. In addition, certain characteristics of the complete blood count (CBC) index may suggest thalassemia characteristics, such as a microcytic anemia and an increase in RBC counts. The $\beta$ thalassemia trait can be diagnosed by detecting elevated $\mathrm{Hb} \mathrm{A} 2$. The $\alpha$ thalassemia profile can be diagnosed by displaying a hemoglobin $\mathrm{H}$ body on a peripheral blood smear using a special stain. In some thalassemia patients with suspected phenotypic outcomes, genetic testing for specific thalassemia mutations may be needed(Akers et al., 2017).

The lifespan of red blood cells refers to the survival period of circulating red blood cells after they are released from the bone marrow. In a healthy individual, the red blood cells survival time after release from the bone marrow is approximately 120 days (García-Roa et al., 2017). In 1919, Winifred Ashby first estimated Measuring red blood cell survival (RBCS) accurately by using the differential agglutination technique (Ashby, 1919). Later, both radioactive isotopes and nonradioactive isotypes were used to label red blood cells to estimate their lifespan (by using ${ }^{51} \mathrm{Cr}$ to determine blood volume and RBCS) (Gray \& Sterling, 1950; Ebaugh et al., 1953). Although this method has been used as the gold standard, it takes weeks to measure RBCS, and it is not safe to use in infants and pregnant woman. Recently, a rapid and noninvasive carbon monoxide (CO) breath test has been developed to determine RBCS (Ma et al., 2016; Mitlyng et al., 2006; Zhang et al., 2018; Karim et al., 2016). CO is byproduct of catablic heme during catabolism and bout $70 \%$ of heme turnover is due to hemoglobin (HGB) decay, therefore measuring the rate of endogenous $\mathrm{CO}$ production can accutatly indicate the red blood cell turnover (Coburn, 2012).

RBCS can be used as an important physiological indicator for the diagnosis of various diseases, such as hemolytic anemia, 
aplastic anemia, Myelodysplastic syndromes anemia, leukemia anemia, renal anemia, hypersplenism and cirrhosis (Franco, 2009). Patients with these diseases usually exhibit a shortened lifespan of red blood cells. The degree of lifespan shortening is related to the type of disease, the progression of the disease, and the degree of hemolysis, thereby revealing the clinical significance of RBCS in the diagnosis and quantitative analysis of anemia hemolytic factors.

The determination of red blood cell life has special significance when it is difficult to diagnose hemolytic anemia or hemolytic disease. Several studies have reported the clinical application of RBCS in multiple diseases, such as hemolysis (Tidmarsh et al., 2014; Christensen et al., 2015), plasma CO levels and heme oxygenase in patients with liver cirrhosis (Tarquini et al., 2009), hemoglobinopathiesassessment (James et al., 2010), diabetes monitoring effect evaluation (Virtue et al., 2004b; Cohen et al., 2008), ribavirin treatment (Virtue et al., 2004a), chronic renal insufficiency hemodialysis (Franco, 2009), and heart valve replacement safety assessment (Mitlyng et al., 2006). The lifespan of red blood cells can reflect the degree of hemolysis of erythrocytes. When the patient is in hemolysis state without anemia symptoms, RBCS value is obviously shortened. Therefore, it is of particular significance to determine RBCS at this time for determining the hemolytic status, screening for thalassemia carriers or identifying hemolytic status caused by chronic diseases (Shrestha et al., 2016).

Recently, a new clinically relevant parameter to assess the quality of transfused red blood cells called Mean Remaining Lifespan (MRL) has been introduced (Kuruvilla et al., 2014). MRL is analogous to the area under the receiver operating characteristic (ROC) curve (AUC) or mean residence time (MRT) in pharmacokinetics (PK) studies. It is defined as the AUC of the fraction of the transfused RBCS remaining in the circulation versus time (Peng et al., 2015). This is in fact an estimate of mean residual lifespan (Mitlyng et al., 2006). In this report, we measured RBCS by CO breath test to help clinically distinguish between iron deficiency anemia (IDA) and thalassemia.

\section{Materials and methods}

\subsection{Study subjects}

From May 2017 to May 2018, a total of 233 patients from the Affiliated Hospital of Southern Medical University were enrolled, including 48 IDA patients (20 males , 28 females, aged 14-86), 60 thalassemia patients ( 30 males, 30 females, aged 6-65), of which 40 were $\beta$-thalassemia ( 30 mild $\beta$-thalassemia and 10 severe $\beta$-thalassemia) and 20 were $\alpha$-thalassemia. The control group included 125 healthy individuals (61 males, 64 females, aged 19-67). This study was approved by the Council of Ethics Committee. The subject has signed an informed consent form.

In the thalassemia group, all patients were confirmed by genetic tests. They did not have chronic inflammation, infection, chronic or malignant diseases. Routine blood results and iron metabolism indicators were not in line with IDA. Exclude Patients if one of the following conditions: active and/or passive smoking 24 hours prior to testing, infection, dysfunctions of heart, lung and liver, acute or chronic bleeding, pregnancy, taking ribavirin or phenobarbital sodium that negatively impact on RBCS, or menstrual period.

\subsection{Devices and instruments}

Gas collection devices and detection instruments were all developed and provided by Shenzhen XianYa Biotechnology Co., Ltd. (Zhang et al., 2018), including (1) RBCS-01 red blood cell lifespan meter; (2) Exhaled gas collection devices: alveolar gas collection bag (1500 ml); cavity gas bag (adult $300 \mathrm{ml}$ ); blow nozzle and three-way catheter; (3) Environmental gas collection bag $(1500 \mathrm{ml})$ and air exit bag.

\subsection{Pulmonary alveolar air collection}

The alveolar air was collected from the patients. Briefly, the patients held the alveolar gas collection device with the end of the blower close to the chest. After taking a deep breath and holding the breath for 10 seconds, patients exhaled completely to the bag at once. Once sufficient air was obtained in the alveolar gas collection bag, the gas collecting device was s removed, sealed and stored at room temperature. All other tests were completed within 5 days.

\subsection{Environmental CO collection}

To rule out exclude the interference of exogenous $\mathrm{CO}$ on end-tidal CO (ETCO) test results, ambient air was collected in the same environment as alveolar gas. Briefly, the investigator pinched the hand pump until the gas collection bag was filled with ambient air, then removed the hand pump and immediately sealed the bag. Samples were stored at room temperature and all other tests were completed within 5 days of collection.

\subsection{Measurement of ETCO and RBCS}

The alveolar gas collection bag and the ambient gas collection bag were connected to the instrument's alveolar gas and base gas air nozzles to measure and record the ETCO and RBCS values. The test process took about 15 minutes.

RBCS was calculated based on CO measurements from the following formula, which equates mean RBC lifespan with the total capacity of $\mathrm{CO}$ from hemoglobin divided by the $\mathrm{CO}$ quantity released per day:

$R B C S=(H G B \times 1380 /$ endPco,

Where HGB is the hemoglobin concentration $(\mathrm{g} / \mathrm{L}), 1380$ is the constant $\mathrm{K}$ and endPco is the mean endogenous $\mathrm{CO}$ production fraction. (Peng et al., 2015; Strauss et al., 2004)

\section{Statistical analysis}

The experimental data were analyzed by SPSS23.0 statistical software. Data normality was determined by KolmogorovSmirnov test. Data obtained from the experimental groups and control group were expressed as means \pm SD. The difference was compared by one way ANOVA followed by the post hoc test. Each comparison was considered statistically significant if $\mathrm{P}<0.05$. Pearson was used for correlation analysis. Diagnostic 
threshold, sensitivity, specificity and area under the curve were calculated by receiver operating characteristic (ROC) curve.

\section{Results}

\subsection{Red blood cell lifespan}

After measuring the alveolar $\mathrm{CO}$ from all subjects, RBCS values were obtained and averaged within each group (Table 1 ). The mean RBCS was $67.5 \pm 22.0$ days for patients with mild $\beta$-thalassemia $(\mathrm{n}=30), 31.3 \pm 13.9$ days for patients with severe $\beta$-thalassemia $(\mathrm{n}=10), 69.3 \pm 27.7$ days for $\alpha$-thalassemia patients $(\mathrm{n}=20)$ and $78.2 \pm 28.2$ days for IDA patients $(n=48)$. The mean RBCS of the control group was $114.3 \pm 33.8$ days. The RBCS value from the thalassemia group showed significant difference compared to IDA group or the control group. The RBCS value from IDA group was also statistically different from the control group.

Other red blood cell indices were also measured (Table 2). The examined HGB, mean corpuscular volume (MCV), mean corpuscular hemoglobin $(\mathrm{MCH})$, mean corpuscular hemoglobin concentration (MCHC) and red cell distribution width (RDW) between thalassemia, IDA and healthy controls were significantly different (except red blood cell (RBC) counts). Compared with IDA patients, thalassemia patients showed significantly different RBC counts, but did not differ from the control group. On the other hand, RBC counts between IDA patients and healthy controls were significantly different. A comparison between thalassemia group and IDA group showed significant differences in HGB level and RDW value.

\subsection{Diagnosis of thalassemia and IDA based on RBCS}

ROC curves were plotted (Figure 1A, B) to obtain the cutoff points with higher sensitivity and specificity for every parameter in thalassemia and IDA diagnosis. The optimal cutoff value was obtained based on AUC and maximum sensitivity and specificity (Table 3 ).
For thalassemia, we found that MCV had the largest AUC (0.976) with the highest sensitivity $(100 \%)$ and the highest specificity (91.2\%). Compared to other parameters, RBCS showed an AUC (0.906) with high sensitivity (82.1\%) and high specificity (80\%). For the diagnosis of thalassemia, the sensitivity and specificity of RBCS were higher than the diagnosis of IDA. Its smallest AUC was MCHC (0.681).

For IDA, the highest sensitivity came from both MCV (97.9\%) and $\mathrm{MCH}$ (97.9\%). The highest specificity came from RDW (99.6\%). The lowest sensitivity and specificity were derived from RBCS (66.7\%) and RBC (78.4\%). HGB showed the largest AUC (0.990) and RBCS showed the second lowest AUC (0.814). The lowest AUC comed from RBC (0.811). According to the results, the best cutoff point for the diagnosis of thalassemia based on index RBCS was $<72.5$ sensitivity $(82.1 \%)$, specificity (80.0\%), Youden's Index (YI) (62.1\%), Positive Likelihood Ratio (LR+) (4.10) and Negative Likelihood Ratio (LR-) (0.22). The best cutoff point for diagnosis of IDA based on index RBCS was $<83.5$, sensitivity (66.7\%), specificity (86.4\%), YI (53.1\%), LR+ (4.90) and LR- (0.39).

The relationship between RBCS and other red blood cell parameters in thalassemia and IDA patients were explored (Table 4). The strongest association between RBCS and RBC was observed in thalassemia patients $(r=0.582, \mathrm{P}<0.001)$ compared with other erythrocyte indices. In IDA patients, the strongest association was observed between RBCS and $\mathrm{MCH}$ $(\mathrm{r}=0.455, \mathrm{P}<0.01)$.

The comparison of $\alpha, \beta$ thalassemia and controls RBCS (Table 1) showed that the mean RBCS of mild $\beta$-thalassemia $(\mathrm{n}=30)$ was $67.5 \pm 22.0$ days, severe $\beta$-thalassemia $(\mathrm{n}=10)$ was $31.3 \pm 13.9$ days, $\alpha$-thalassemia $(\mathrm{n}=20)$ was $69.3 \pm 27.7$ days and IDA was $78.2 \pm 28.2$ days. The RBCS value of the control group was $114.3 \pm 33.8$ days. The RBCS values of all thalassemia and IDA groups were significantly different from the RBCS values of the control group. There was a statistically significant difference

Table 1. Comparison of RBCS between different types of thalassemia and controls (mean \pm SD).

\begin{tabular}{ccccc}
\hline Group & Subjects\# & RBCS(day) & range(day) & $95 \%$ CI \\
\hline Thalassemia & 60 & $60.8 \pm 27.9^{\mathrm{a}, \mathrm{b}}$ & $32 \sim 100$ & \\
Mild $\beta$-thalassemia & 30 & $67.5 \pm 22.0^{\mathrm{a}}$ & & \\
Severe $\beta$-thalassemia & 10 & $30.2 \pm 13.9^{\mathrm{a}, \mathrm{c}}$ & & \\
$\alpha$-thalassemia & 20 & $69.3 \pm 27.7^{\mathrm{a}, \mathrm{d}}$ & $60 \sim 119$ & $24 \sim 133$ \\
IDA & 48 & $78.2 \pm 28.2^{\mathrm{a}}$ & $75 \sim 220$ & $50 \sim 180$ \\
Control & 125 & $114.3 \pm 33.8$ & & \\
\hline
\end{tabular}

RBCS = red blood cell survival; IDA = iron deficiency anemia; a Compared with controls, $\mathrm{P}<0.05 ; \mathrm{b}$ Compared with mild $\mathrm{b}$-thalassemia, $\mathrm{P}<0.05 ; \mathrm{c}$ Compared with severe $\mathrm{b}$-thalassemia, $\mathrm{P}<0.05$; d Compared with a-thalassemia, $\mathrm{P}<0.05$.

Table 2. Comparison of red blood cell indices in each group (mean \pm SD).

\begin{tabular}{|c|c|c|c|c|c|c|c|}
\hline Groups & Subjects & $\begin{array}{c}\mathrm{RBC} \\
\left(\times 10^{12} / \mathrm{L}\right)\end{array}$ & $\begin{array}{l}\text { HGB } \\
(\mathrm{g} / \mathrm{L})\end{array}$ & $\begin{array}{c}\text { MCV } \\
\text { (fl) }\end{array}$ & $\begin{array}{c}\mathrm{MCH} \\
(\mathrm{pg})\end{array}$ & $\begin{array}{c}\mathrm{MCHC} \\
(\mathrm{g} / \mathrm{L})\end{array}$ & $\begin{array}{c}\text { RDW } \\
(\%)\end{array}$ \\
\hline Thalassemia & 60 & $5.27 \pm 1.11^{b}$ & $110 \pm 19.04^{\mathrm{a}, \mathrm{b}}$ & $68.9 \pm 7.84^{\mathrm{a}}$ & $21.9 \pm 3.74^{\mathrm{a}}$ & $316 \pm 25.71^{\mathrm{a}, \mathrm{b}}$ & $16.7 \pm 3.35^{\mathrm{a}, \mathrm{b}}$ \\
\hline IDA & 48 & $4.09 \pm 0.67^{\mathrm{a}}$ & $88 \pm 21.07^{\mathrm{a}}$ & $73.0 \pm 8.60^{\mathrm{a}}$ & $21.5 \pm 3.51^{\mathrm{a}}$ & $293 \pm 20.95^{\mathrm{a}}$ & $18.5 \pm 3.46^{\mathrm{a}}$ \\
\hline Control & 125 & $4.85 \pm 0.54$ & $142 \pm 18.84$ & $90.9 \pm 6.26$ & $31.4 \pm 10.18$ & $325 \pm 10.64$ & $12.85 \pm 0.75$ \\
\hline
\end{tabular}

$\mathrm{IDA}=$ iron deficiency anemia; $\mathrm{RBC}=$ red blood cell; $\mathrm{HGB}=$ hemoglobin; $\mathrm{MCV}=$ mean corpuscular volume; $\mathrm{MCH}=$ mean corpuscular hemoglobin; $\mathrm{MCHC}=$ mean corpuscular

hemoglobin concentration; RDW $=$ red cell distribution width; a Compared with the control group, $\mathrm{P}<0.05$; b Compared with IDA group, $\mathrm{P}<0.05$. 
ROC Curve

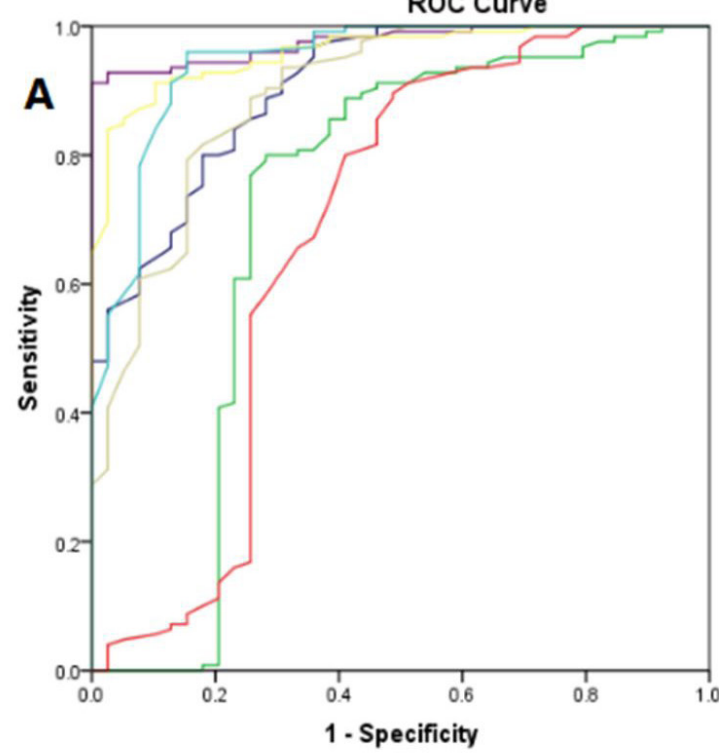

ROC Curve

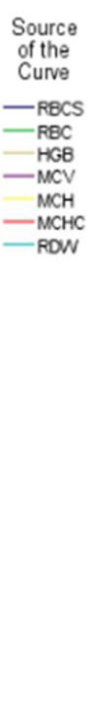

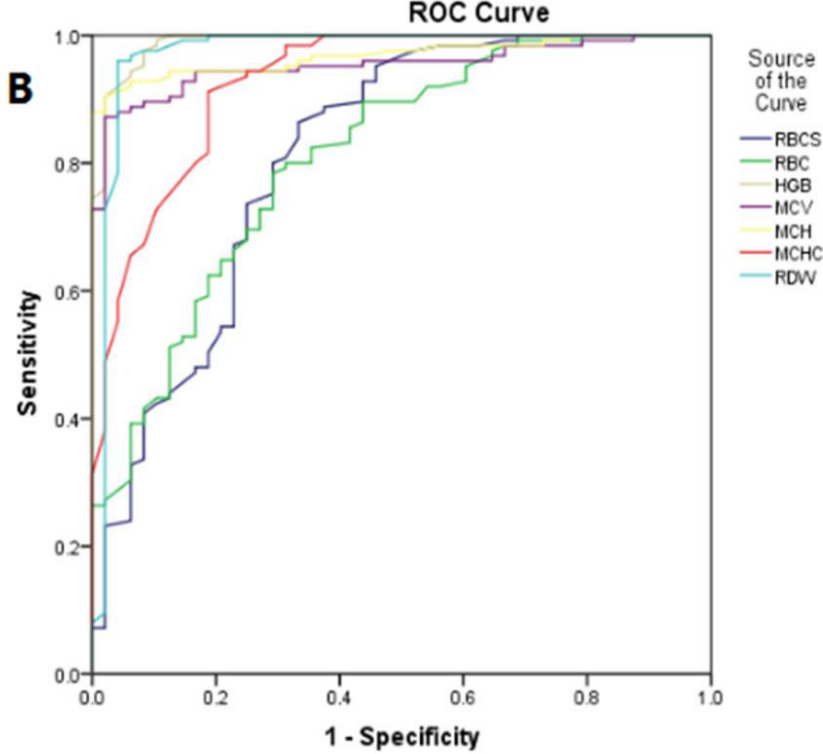

Figure 1. (A) receiver operating characteristic curve of red blood cell survival, hemoglobin, mean corpuscular volume, mean corpuscular hemoglobin, mean corpuscular hemoglobin concentration, red cell distribution width and red cell counts in the diagnosis of thalassemia. RBCS: red blood cell survival; RBC: red blood cell; HGB: hemoglobin; MCV: mean corpuscular volume; MCH: mean corpuscular hemoglobin; MCHC: mean corpuscular hemoglobin concentration; RDW: red cell distribution width; (B) receiver operating characteristic curve of red blood cell survival and red blood cell parameters in the iron deficiency anemia diagnosis. RBCS: red blood cell survival; RBC: red blood cell; HGB: hemoglobin; MCV: mean corpuscular volume; $\mathrm{MCH}$ : mean corpuscular hemoglobin; MCHC: mean corpuscular hemoglobin concentration; RDW: red cell distribution width.

Table 3. Performance of different indices in diagnosis of IDA and thalassemia.

\begin{tabular}{cccccccc}
\hline Index & Cut-off & $\begin{array}{c}\text { AUC } \\
(95 \% \text { CI })\end{array}$ & $\begin{array}{c}\text { SEN\% } \\
(95 \% \text { CI })\end{array}$ & $\begin{array}{c}\text { SPE\% } \\
(95 \% \text { CI })\end{array}$ & YI\% & $\begin{array}{c}\text { LR+ } \\
(95 \% \text { CI })\end{array}$ & $\begin{array}{c}\text { LR- } \\
(95 \% \text { CI })\end{array}$ \\
\hline RBCS & Thalassemia $<72.5$ & 0.906, & $82.1(81.3-83.4)$ & $80.0(79.3-81.2)$ & 62.1 & $4.10(3.93-4.43)$ & $0.22(0.20-0.23)$ \\
& IDA $<83.5$ & 0.814 & $66.7(64.1-67.6)$ & $86.4(85.1-85.4)$ & 53.1 & $4.90(4.30-4.63)$ & $0.39(0.37-0.42)$ \\
RBC & Thalassemia $>5.24$ & 0.712 & $71.8(70.3-72.4)$ & $80.0(78.7-82.3)$ & 51.8 & $3.59(3.30-4.01)$ & $0.35(0.33-0.37)$ \\
& IDA $<4.41$ & 0.811 & $70.8(69.3-71.1)$ & $78.4(77.7-79.8)$ & 49.2 & $3.28(3.10-3.51)$ & $0.37(0.36-0.39)$ \\
HGB & Thalassemia $<130.5$ & 0.895 & $84.6(82.9-85.9)$ & $79.2(78.3-81.3)$ & 63.8 & $4.06(3.82-4.59)$ & $0.19(0.17-0.21)$ \\
& IDA $<114$ & 0.990 & $91.7(90.1-92.9)$ & $97.6(96.1-98.7)$ & 89.3 & $38.21(23.1-71.46)$ & $0.09(0.07-0.10)$ \\
MCV & Thalassemia $<84.6$ & 0.976 & $100(98.9-100)$ & $91.2(90.8-92.6)$ & 91.2 & $11.36(10.75-13.51)$ & $0.00(0.00-0.01)$ \\
& IDA $<86.9$ & 0.953 & $97.9(96.4-99.1)$ & $87.2(86.9-89.0)$ & 85.1 & $7.65(7.35-9.00)$ & $0.02(0.01-0.04)$ \\
MCH & Thalassemia $<28.8$ & 0.960 & $97.4(95.9-98.7)$ & $84.0(83.1-85.4)$ & 81.4 & $6.09(5.67-6.76)$ & $0.02(0.02-0.05)$ \\
& IDA $<27.7$ & 0.968( & $97.9(96.3-98.8)$ & $90.4(89.1-92.2)$ & 88.3 & $10.20(8.83-12.66)$ & $0.02(0.01-0.04)$ \\
MCHC & Thalassemia $<313.5$ & 0.681 & $51.3(50.1-52.7)$ & $89.6(88.4-91.9)$ & 40.9 & $4.93(4.31-6.50)$ & $0.54(0.51-0.56)$ \\
& IDA $<312$ & 0.928 & $81.3(80.2-82.4)$ & $91.2(89.2-92.8)$ & 72.5 & $9.24(7.44-11.15)$ & $0.21(0.18-0.22)$ \\
RDW & Thalassemia $>14.1$ & 0.946 & $84.6(83.5-86.0)$ & $96.0(95.4-97.6)$ & 80.6 & $21.15(18.15-35.83)$ & $0.16(0.14-0.17)$ \\
& IDA $>14.1$ & 0.973 & $95.8(94.3-97.1)$ & $99.6(98.1-99.9)$ & 91.8 & $239.5(49.63-971.0)$ & $0.04(0.03-0.06)$
\end{tabular}

IDA = iron deficiency anemia; $\mathrm{RBCS}=$ red blood cell survival; $\mathrm{RBC}=$ red blood cell; $\mathrm{HGB}=$ hemoglobin; $\mathrm{MCV}=$ mean corpuscular volume; $\mathrm{MCH}=$ mean corpuscular hemoglobin; $\mathrm{MCHC}=$ mean corpuscular hemoglobin concentration; RDW = red cell distribution width; $\mathrm{AUC}=$ area under the ROC curve; $\mathrm{SEN}=\mathrm{sensitivity}$; SPE = specificity; YI = Youden's index; LR+ = Positive Likelihood Ratio; LR- = Negative Likelihood Ratio

in RBCS between patients with severe $\beta$-thalassemia and those with mild $\beta$ - or $\alpha$-thalassemia and IDA.

\section{Discussion}

Microcytic hypochromic anemia is a type of anemia characterized by smaller sized red blood cells. IDA and thalassemia syndromes are the two most common etiologies of microcytic hypochromic anemia in children and adults (Dolai et al., 2012; El-Agouza et al., 2002). While transfusions are more common in premature infants with approximately $40 \%$ of low birth weight infants and up to $90 \%$ of extremely low birth weight infants requiring red blood cell transfusion (Valancy et al., 2021; Villeneuve et al., 2021). Patients with both conditions 
Table 4. Correlation between RBCS and erythrocyte parameters in thalassemia and IDA patients.

\begin{tabular}{|c|c|c|c|c|c|c|c|c|c|c|c|}
\hline \multirow[t]{2}{*}{ Groups } & \multicolumn{2}{|c|}{$\begin{array}{c}\text { RBCS vs. } \\
\text { RBC }\end{array}$} & \multicolumn{2}{|c|}{$\begin{array}{c}\text { RBCS vs. } \\
\text { HGB }\end{array}$} & \multicolumn{2}{|c|}{ RBCS vs. MCV } & \multicolumn{2}{|c|}{ RBCS vs. $\mathrm{MCH}$} & \multicolumn{2}{|c|}{ RBCS vs. MCHC } & $\begin{array}{c}\text { RBCS vs. } \\
\text { RDW }\end{array}$ \\
\hline & $r$ & $P$ & $r$ & $P$ & $r$ & $P$ & $r$ & $P$ & $r$ & $P$ & $r$ \\
\hline $\begin{array}{l}\text { Thalassemia } \\
(\mathrm{n}=60)\end{array}$ & 0.582 & 0.000 & 0.577 & 0.000 & -0.323 & 0.045 & -0.255 & 0.117 & 0.008 & 0.959 & -0.240 .142 \\
\hline $\begin{array}{l}\text { IDA } \\
(\mathrm{n}=48)\end{array}$ & 0.212 & 0.149 & 0.449 & 0.001 & 0.400 & 0.005 & 0.455 & 0.001 & 0.384 & 0.007 & 0.3370 .019 \\
\hline
\end{tabular}

IDA = iron deficiency anemia; RBCS = red blood cell survival; RBC = red blood cell; $\mathrm{HGB}=$ hemoglobin; $\mathrm{MCV}=$ mean corpuscular volume; $\mathrm{MCH}=$ mean corpuscular hemoglobin; $\mathrm{MCHC}=$ mean corpuscular hemoglobin concentration; RDW $=$ red cell distribution width; $r=$ correlation coefficient.

may exhibit morphologically similar red blood cell and anemia symptoms. Therefore, physicians often mistake mild thalassemia for IDA and prescribe unnecessary iron supplements (Keramati \& Maybodi, 2007; Jameel et al., 2017). Red blood cell indices such as MCV, MCH, MCHC, RDW and blood morphology have been used in differentiation of IDA, thalassemia, and other hemolytic anemias (Nalbantoğlu et al., 2012; Verma et al., 2014). However, these indicators vary in efficiency and have poor repeatability. The threshold for the same index also varies from region to region.

In this paper, we have analyzed the value of RBCS in the diagnosis and differential diagnosis of thalassemia and IDA through $\mathrm{CO}$ breath test. The mean RBCS from patients with thalassemia was significantly different from of the mean for IDA patients. The RBCS values of thalassemia and IDA patients were significantly lower than the control group. The optimal cutoff points for thalassemia and IDA were $<72.5$ and $<83.5$, respectively, which can be used to identify thalassemia or IDA. For the diagnosis of thalassemia, the sensitivity and specificity of RBCS were higher than the diagnosis of IDA. Sensitivity and specificity are the probabilities of accurately identifying individuals with or without a disease at a cut-off point. In thalassemia testing, highly sensitive and specific RBCS indicates that it is a good detection for this disease.

The YI of RBCS in both thalassemia (62.1\%) and IDA (53.1\%) showed that RBCS was a potentially effective tool for diagnosis of both disease. The LR+ value in diagnosis for thalassemia (4.10) and IDA (4.90) indicated that the probability of using RBCS to diagnose both diseases at the predicted cut-off point is small. The LR- value in diagnosis of thalassemia (0.22) and IDA (0.39) suggested that the probability of diagnosing these patients was moderate based on the predicted RBCS threshold.

In thalassemia, MCV showed the largest AUC with the greatest sensitivity and specificity. ROC curve indicated that RBCS could be used as a new indicator for primary screening of thalassemia. Meanwhile, based on Pearson correlation coefficient and $\mathrm{P}$ value, $\mathrm{RBCS}$ was significantly positively correlated with RBC count and HGB, moderately positively correlated with MCV, and weakly positively correlated with $\mathrm{MCH}, \mathrm{MCHC}$ and RDW.

In IDA, RBCS showed a moderate positive correlation with $\mathrm{HGB}, \mathrm{MCV}, \mathrm{MCH}, \mathrm{MCHC}$, and $\mathrm{RDW}$ and a weak positive correlation with RBC. Our results indicated that although RBCS cannot be used to distinguish between $\alpha$-thalassemia and mild $\beta$-thalassemia, there was a significant difference between severe $\beta$-thalassemia and mild $\beta$-thalassemia and severe $\beta$-thalassemia and $\alpha$-thalassemia and severe $\beta$-thalassemia and IDA patients. Therefore, RBCS can be used to distinguish between different types of thalassemia.

The standard label for measuring red blood cell lifespan, such as ${ }^{51} \mathrm{Cr}$, is well suited for research applications, but not in clinical use, as there is a radioactive risk to both patients and staff, due to the length of measurement and the requirement for frequent blood collection. The alveolar $\mathrm{CO}$ breath test brings a new breakthrough in the determination of erythrocyte lifespan in vivo. It enhances direct determination of the survival of red blood cell, making it possible to detect large sample patients and improving the basic research and clinical diagnosis of diseases associated with shortened erythrocytes lifespan.

Thalassemia is a genetic disorder that can result in a decrease disappearance of HGB in red blood cells. Erythrocyte lifespan of these patients is usually short, leading to microcytic anemia. IDA affects the synthesis of heme, which in turn limits the synthesis of HGB in red blood cells. Studies also shown that IDA enhances oxidative stress level in red blood cells and that subsequent generation of Reactive Oxygen Species (ROS) can shortern lifespan of red blood cells (Arias \& Arias, 2017; Kuhn et al., 2017). The current screening for IDA and thalassemia is by the use of HGB electrophoresis, body iron metabolism, bone biopsy and gene detection of thalassemia, and these technical requirements are high and the reporting time is long. Measuring RBCS through CO breath test is a fast and non-invasive method.

In conclusion, RBCS provides an excellent diagnostic accuracy through $\mathrm{CO}$ breath test. Combined with other red blood cell indices, the use of RBCS contributes to the clinical differential diagnosis of thalassemia and IDA, distinguishing between severe $\beta$-thalassemia and mild $\beta$-thalassemia or $\alpha$-thalassemia. More work needs to be done to clarify whether RBCS can be used to aid in the diagnosis of other diseases associated with shortened erythrocytes lifespan. The determination of erythrocyte lifespan will contribute to a comprehensive analysis of the etiology of anemia and serve as guide for customized treatment options.

\section{Conflict of interest}

The authors have declared that no competing interests exist.

\section{Funding}

The study was supported by Innovation Fund for Technology Based Firms, the Ministry of Science and Technology, PR China (NO.13C1217, Code. 10c26214424838); Shenzhen S\&T 
Program (NO.JCYJ20140415151845365); Health and Family Planning Commission of Shenzhen Municipality (201601040); Medical Scientific Research Foundation of Guangdong Province (A2017143); National Natural Science Foundation of China, Grant/Award Number: 81702088; The work is supported by High-level Hospital Construction Research Project of Maoming People's Hospital. The funders had no role in study design, data collection and analysis, decision to publish, or preparation of the manuscript.

\section{References}

Akers, A. S., Howard, D., \& Ford, J. (2017) Distinguishing iron deficiency anaemia from thalassemia trait in clinical obstetric practice. Journal of Pregnancy and Reproduction, 6(1), 1-6.

Arias, C. F., \& Arias, C. F. (2017). How do red blood cells know when to die? Royal Society Open Science, 4(4), 160850. http://dx.doi. org/10.1098/rsos.160850. PMid:28484605.

Ashby, W. (1919). The determination of the length of life of transfused blood corpuscles in man. The Journal of Experimental Medicine, 29(3), 267-281. http://dx.doi.org/10.1084/jem.29.3.267. PMid:19868318.

Christensen, R. D., Lambert, D. K., Henry, E., Yaish, H. M., \& Prchal, J. T. (2015). End-tidal carbon monoxide as an indicator of the hemolytic rate. Blood Cells, Molecules \& Diseases, 54(3), 292-296. http://dx.doi.org/10.1016/j.bcmd.2014.11.018. PMid:25624169.

Coburn, R. F. (2012). The measurement of endogenous carbon monoxide production. Journal of Applied Physiology, 112(11), 1949-1955. http://dx.doi.org/10.1152/japplphysiol.00174.2012. PMid:22442030.

Cohen, R. M., Franco, R. S., Khera, P. K., Smith, E. P., Lindsell, C. J., Ciraolo, P. J., Palascak, M. B., \& Joiner, C. H. (2008). Red cell life span heterogeneity in hematologically normal people is sufficient to alter HbA1c. Blood, 112(10), 4284-4291. http://dx.doi.org/10.1182/ blood-2008-04-154112. PMid:18694998.

Dolai, T. K., Nataraj, K. S., Sinha, N., Mishra, S., Bhattacharya, M., \& Ghosh, M. K. (2012). Prevalence of iron deficiency in thalassemia minor: a study from tertiary hospital. Indian Journal of Hematology \& Blood Transfusion, 28(1), 7-9. http://dx.doi.org/10.1007/s12288011-0088-9. PMid:23449336.

Ebaugh, F. G. Jr, Emerson, C. P., Ross, J. F., Aloia, R., Halperin, P., \& Richards, H. (1953). The use of radioactive chromium 51 as an erythrocyte tagging agent for the determination or red cell survival in vivo. The Journal of Clinical Investigation, 32(12), 1260-1276. http://dx.doi.org/10.1172/JCI102855. PMid:13108994.

El-Agouza, I., Shahla, S. A., \& Sirdah, M. (2002). The effect of iron deficiency anaemia on the levels of haemoglobin subtypes: possible consequences for clinical diagnosis. Clinical and Laboratory Haematology, 24(5), 285-289. http://dx.doi.org/10.1046/j.13652257.2002.00464.x. PMid:12358889.

Franco, R. S. (2009). The measurement and importance of red cell survival. American Journal of Hematology, 84(2), 109-114. http:// dx.doi.org/10.1002/ajh.21298. PMid:19025796.

García-Roa, M., Vicente-Ayuso, M. C., Bobes, A. M., Pedraza, A. C., González-Fernández, A., Martín, M. P., Sáez, I., Seghatchian, J., \& Gutiérrez, L. (2017). Red blood cell storage time and transfusion: current practice, concerns and future perspectives. Blood Transfusion, 15(3), 222-231. PMid:28518049.

Gray, S. J., \& Sterling, K. (1950). Determination of circulating red cell volume by radioactive chromium. Science, 112(2902), 179-180. http://dx.doi.org/10.1126/science.112.2902.179. PMid:15442294.
Jameel, T., Baig, M., Ahmed, I., Hussain, M. B., \& Alkhamaly, M. B. D. (2017). Differentiation of beta thalassemia trait from iron deficiency anemia by hematological indices. Pakistan Journal of Medical Sciences, 33(3), 665-669. http://dx.doi.org/10.12669/pjms.333.12098. PMid:28811791.

James, E. B., Vreman, H. J., Wong, R. J., Stevenson, D. K., Vichinsky, E., Schumacher, L., Hall, J. Y., Simon, J., Golden, D. W., \& Harmatz, P. (2010). Elevated exhaled carbon monoxide concentration in hemoglobinopathies and its relation to red blood cell transfusion therapy. Pediatric Hematology and Oncology, 27(2), 112-121. http:// dx.doi.org/10.3109/08880010903536227. PMid:20201692.

Karim, M. F., Ismail, M., Hasan, A. M., \& Shekhar, H. U. (2016). Hematological and biochemical status of Beta-thalassemia major patients in Bangladesh: a comparative analysis. International Journal of Hematology-Oncology and Stem Cell Research, 10(1), 7-12. PMid:27047645.

Keramati, M. R., \& Maybodi, N. T. (2007). The effect of Iron Deficiency Anemia (IDA) on the $\mathrm{HbA} 2$ level and comparison of hematologic values between IDA and thalassemia minor. International Journal of Hematologic Oncology, 17(3), 151-156.

Kuhn, V., Diederich, L., Keller, T. C. S. 4th, Kramer, C. M., Lückstädt, W., Panknin, C., Suvorava, T., Isakson, B. E., Kelm, M., \& CorteseKrott, M. M. (2017). Red blood cell function and dysfunction: redox regulation, nitric oxide metabolism, anemia. Antioxidants \& Redox Signalling, 26(13), 718-742. http://dx.doi.org/10.1089/ars.2016.6954. PMid:27889956.

Kuruvilla, D. J., Nalbant, D., Widness, J. A., \& Veng-Pedersen, P. (2014). Mean remaining life span: a new clinically relevant parameter to assess the quality of transfused red blood cells. Transfusion, 54(10 Pt 2), 2724-2729. http://dx.doi.org/10.1111/trf.12562. PMid:24611672.

Ma, Y. J., Zhang, H. D., Ji, Y. Q., Zhu, G. L., Huang, J. L., Du, L. T., Cao, P., Zang, D. Y., Du, J. H., Li, R., \& Wang, L. (2016). A modified carbon monoxide breath test for measuring erythrocyte lifespan in small animals. BioMed Research International, 2016, 7173156. http://dx.doi.org/10.1155/2016/7173156. PMid:27294128.

Mitlyng, B. L., Chandrashekhar, Y., Furne, J. K., \& Levitt, M. D. (2006). Use of breath carbon monoxide to measure the influence of prosthetic heart valves on erythrocyte survival. The American Journal of Cardiology, 97(9), 1374-1376. http://dx.doi.org/10.1016/j. amjcard.2005.11.074. PMid:16635614.

Nalbantoğlu, B., Güzel, S., Büyükyalçın, V., Donma, M. M., Güzel, E. Ç., Nalbantoğlu, A., Karasu, E., \& Özdilek, B. (2012). Indices used in differentiation of thalassemia trait from iron deficiency anemia in pediatric population: are they reliable? Pediatric Hematology and Oncology, 29(5), 472-478. http://dx.doi.org/10.3109/08880018.201 2.705230. PMid:22866672.

Peng, Y. F., Zhang, Z. X., Cao, W., Meng, C. R., Xu, S. S., \& Zhang, Q. (2015). The association between red blood cell distribution width and acute pancreatitis associated lung injury in patients with acute pancreatitis. Open Medicine, 10(1), 176-179. http://dx.doi.org/10.1515/ med-2015-0028. PMid:28352692.

Rapido, F. (2017). The potential adverse effects of haemolysis. Blood Transfusion, 15(3), 218-221. PMid:28518048.

Shrestha, R. P., Horowitz, J., Hollot, C. V., Germain, M. J., Widness, J. A., Mock, D. M., Veng-Pedersen, P., \& Chait, Y. (2016). Models for the red blood cell lifespan. Journal of Pharmacokinetics and Pharmacodynamics, 43(3), 259-274. http://dx.doi.org/10.1007/ s10928-016-9470-4. PMid:27039311.

Strauss, R. G., Mock, D. M., Widness, J. A., Johnson, K., Cress, G., \& Schmidt, R. L. (2004). Posttransfusion 24-hour recovery and subsequent survival of allogeneic red blood cells in the bloodstream 
of newborn infants. Transfusion, 44(6), 871-876. http://dx.doi. org/10.1111/j.1537-2995.2004.03393.x. PMid:15157254.

Tarquini, R., Masini, E., La Villa, G., Barletta, G., Novelli, M., Mastroianni, R., Romanelli, R. G., Vizzutti, F., Santosuosso, U., \& Laffi, G. (2009). Increased plasma carbon monoxide in patients with viral cirrhosis and hyperdynamic circulation. The American Journal of Gastroenterology, 104(4), 891-897. http://dx.doi.org/10.1038/ ajg.2009.2. PMid:19277027.

Tidmarsh, G. F., Wong, R. J., \& Stevenson, D. K. (2014). End-tidal carbon monoxide and hemolysis. Journal of Perinatology, 34(8), 577-581.

Valancy, D., Blachman-Braun, R., Kuchakulla, M., Nackeeran, S., \& Ramasamy, R. (2021). Association between low testosterone and anaemia: analysis of the National Health and Nutrition Examination Survey. Andrologia, e14210. PMid:34374113.

Verma, S., Gupta, R, Kudesia, M, Mathur, A, Krishan, G, \& Singh, S. (2014). Coexisting iron deficiency anemia and beta thalassemia trait: effect of iron therapy on red cell parameters and hemoglobin subtypes. SRN Hematology, 2014, 293216.
Villeneuve, A., Arsenault, V., Lacroix, J., \& Tucci, M. (2021). Neonatal red blood cell transfusion. Vox Sanguinis, 116(4), 366-378. http:// dx.doi.org/10.1111/vox.13036. PMid:33245826.

Virtue, M. A., Furne, J. K., Ho, S. B., \& Levitt, M. D. (2004a). Use of alveolar carbon monoxide to measure the effect of ribavirin on red blood cell survival. American Journal of Hematology, 76(2), 107-113. http://dx.doi.org/10.1002/ajh.20069. PMid:15164374.

Virtue, M. A., Furne, J. K., Nuttall, F. Q., \& Levitt, M. D. (2004b). Relationship between $\mathrm{GHb}$ concentration and erythrocyte survival determined from breath carbon monoxide concentration. Diabetes Care, 27(4), 931-935. http://dx.doi.org/10.2337/diacare.27.4.931. PMid:15047651.

Zhang, H. D., Ma, Y. J., Liu, Q. F., Ye, T. Z., Meng, F. Y., Zhou, Y. W., Yu, G. P., Yang, J. P., Jiang, H., Wang, Q. S., Li, G. P., Ji, Y. Q., Zhu, G. L., Du, L. T., \& Ji, K. M. (2018). Human erythrocyte lifespan measured by Levitt's CO breath test with newly developed automatic instrument. Journal of Breath Research, 12(3), 036003. http://dx.doi. org/10.1088/1752-7163/aaacf1. PMid:29400658. 